Document downloaded from:

http://hdl.handle.net/10251/96963

This paper must be cited as:

Manuel Pineda-Sanchez; Riera-Guasp, M.; José Roger-Folch; J. Antonino-Daviu; PérezCruz, J.; Rubén Puche-Panadero (2011). Diagnosis of Induction Motor Faults in TimeVarying Conditions Using the Polynomial-Phase Transform of the Current. IEEE Transactions on Industrial Electronics. 58(4):1428-1439. doi:10.1109/TIE.2010.2050755

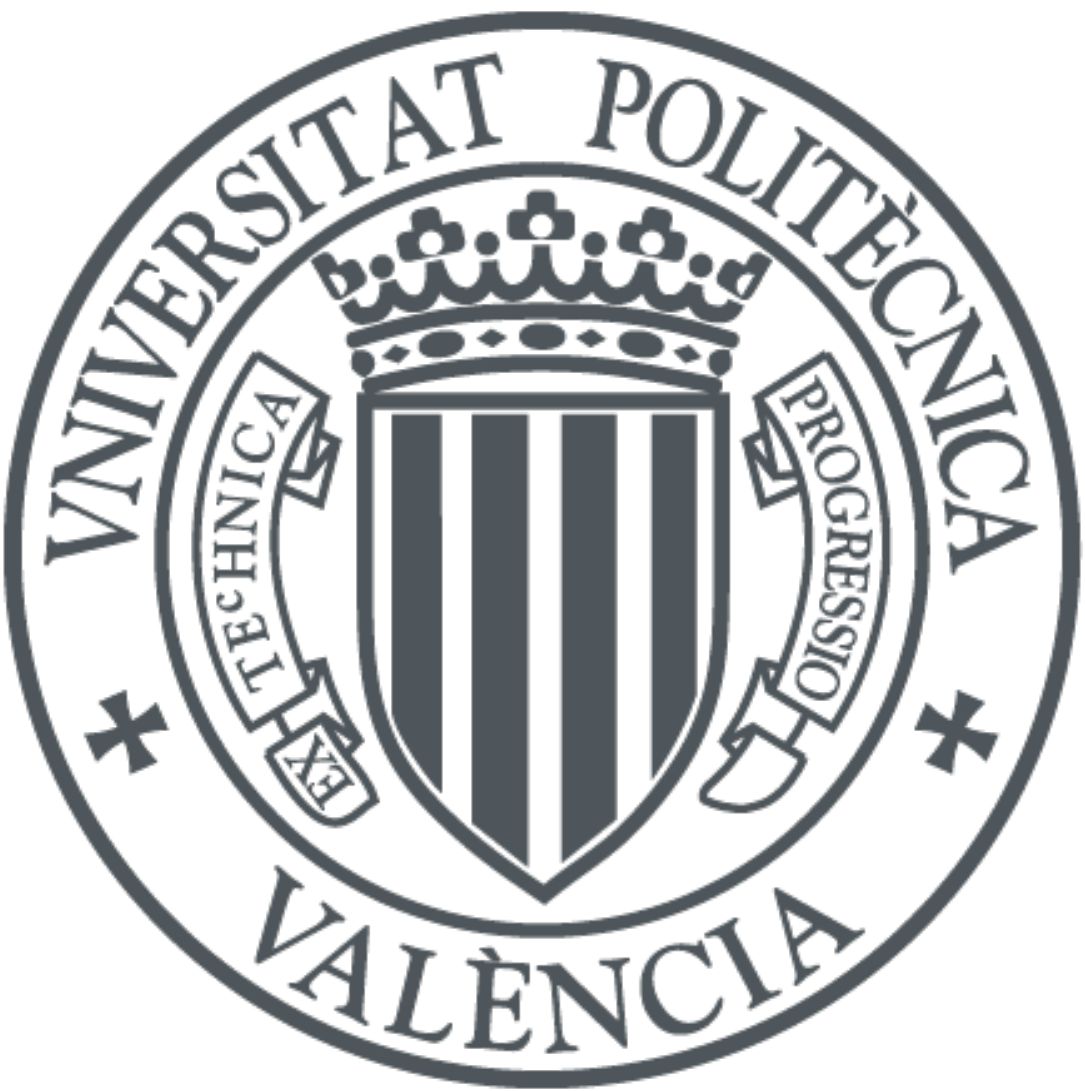

The final publication is available at

http://doi.org/10.1109/TIE.2010.2050755

Copyright Institute of Electrical and Electronics Engineers

Additional Information 


\title{
Diagnosis of Induction Motor Faults in Time- Varying Conditions using the Polynomial-Phase Transform of the Current
}

\author{
M. Pineda-Sanchez, Member, IEEE, M. Riera-Guasp, Member, IEEE, J. Roger-Folch, Member, IEEE, J.A. \\ Antonino-Daviu, Member, IEEE, J. Perez-Cruz, Member, IEEE, and R. Puche-Panadero, Member, IEEE
}

\begin{abstract}
Transient motor current signature analysis is a recently developed technique for motor diagnostics using speed transients. The whole speed range is used to create a unique stamp of each fault harmonic in the time-frequency plane. This greatly increases the diagnostic reliability when compared with non-transient analysis, which is based on the detection of fault harmonics at a single speed. But this added functionality comes at a price: the well established signal analysis tools used in the permanent regime, mainly the Fourier transform, cannot be applied to the non-stationary currents of a speed transient. In this paper, a new method is proposed to fill this gap. By applying a polynomial-phase transform to the transient current, a new, stationary signal is generated. This signal contains information regarding the fault components along the different regimes covered by the transient, and can be analyzed using the Fourier transform. The polynomial-phase transform is used in radar, sonar, communications and power systems fields, but this is the first time, to the best knowledge of the authors, that it has been applied to the diagnosis of induction motor faults. Experimental results obtained with two different commercial motors with broken bars are presented to validate the proposed method.
\end{abstract}

Index terms-Fourier transforms, fault diagnosis, induction motors, signal analysis, frequency modulation, polynomial transforms.

\section{NOMENCLATURE}

A Amplitude of a signal.

$a_{m} \quad m$-th coefficient of the polynomial approximation of the instantaneous phase of a signal.

$b \quad$ Modulation rate of a linearly modulated frequency (LMF) signal.

$\hat{b} \quad$ Estimation of the LMF rate.

$\hat{b}_{1} \quad$ Estimation of the LMF rate of the descending branch of the Left Sideband Harmonic during startup (LSHst).

$\hat{b}_{2} \quad$ Estimation of the LMF rate of the ascending branch of the LSHst.

$f \quad$ Frequency.

$f_{1} \quad$ Power supply frequency.

$f_{b} \quad$ Frequency of the fault components produced by bar breakages.

$f_{i} \quad$ Frequency of the fault components produced by inner race damage in the bearing.

$f_{L S H} \quad$ Frequency of the LSH.

Manuscript received August 17, 2009. Accepted for publication April 27, 2010.

Copyright (C) 2009 IEEE. Personal use of this material is permitted. However, permission to use this material for any other purposes must be obtained from the IEEE by sending a request to pubs-permissions@ieee.org.

This work was supported by the Spanish "Ministerio de Educación y Ciencia" in the framework of the "Programa Nacional de Proyectos de Investigación Fundamental", project reference DPI2008-06583/DPI.

The authors are with the Department of Electrical Engineering, Universidad Politécnica de Valencia, Valencia, 46022 Spain (e-mails: mpineda@die.upv.es, mriera@die.upv.es, jroger@die.upv.es, joanda@die.upv.es, juperez@die.upv.es),rupucpa@die.upv.es. 
$f_{M E} \quad$ Frequency of the fault components produced by mixed eccentricity.

$f_{o} \quad$ Frequency of the fault components produced by outer race damage in the bearing.

$f_{s} \quad$ Sampling frequency.

$M \quad$ Order of the polynomial approximation of the instantaneous phase of a signal.

$N \quad$ Number of samples of the sampled signal.

$N_{b} \quad$ Number of balls in a bearing.

$n_{f} \quad$ Decomposition level of the approximation signal that includes the LSHst.

$p \quad$ Number of pole pairs.

$P_{M} \quad M$-order polynomial-phase transform.

$s \quad$ Slip.

$T \quad$ Upper limit of the interval which is defines the polynomial-phase signal.

$t$ Time.

$\boldsymbol{x} \quad$ Vector containing the $N$ samples of a sampled signal.

$x(t) \quad$ Generic signal with constant amplitude and continuous phase.

$\tau \quad$ Time delay

$\tau_{o p} \quad$ Optimal value of the time delay

$\phi(t) \quad$ Instantaneous phase of a signal.

$\phi^{\prime}(t) \quad$ Instantaneous frequency of a signal.

\section{INTRODUCTION}

otor current signature analysis (MCSA) is a well established [1]-[8] and reliable methodology for

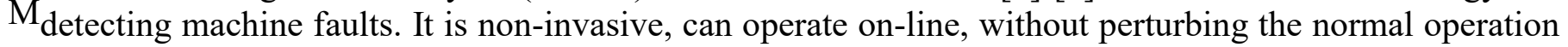
of the motor being diagnosed, and it is simple to apply because only a current probe is needed to capture the motor current. Each type of fault produces oscillations in the motor current whose characteristic frequencies have been established theoretically. In particular, rotor bar breakages generate oscillations of frequency

$$
f_{b}(s)=(k / p(1-s) \pm s) f_{1} \text { with } k / p=1,3,5 \ldots
$$

where $f_{1}$ is the power supply frequency, $s$ is the slip and $p$ is the number of the machine pole pairs. The harmonic with the lowest order in (1), known as the Left Sideband Harmonic (LSH), is the most commonly used in MCSA to detect a broken bar fault. Its frequency is given by

$$
f_{L S H}(s)=\left|f_{1}(1-2 s)\right|
$$

Other types of faults also generate harmonics whose frequency varies linearly with the slip. For example, in the case of mixed eccentricity,

$$
f_{M E}(s)=f_{1} \pm(1-s) f_{1} / p
$$

or, in the case of cyclic faults in the outer and inner races of bearings (for bearings with between 6 and 12 balls), the rate of variation of the characteristic frequencies is [9]

$$
\begin{aligned}
& \text { Outer race: } f_{o}(s)=0.4 N_{b}(1-s) f_{1} / p \\
& \text { Inner race: } f_{i}(s)=0.6 N_{b}(1-s) f_{1} / p
\end{aligned}
$$


where $N_{b}$ is the number of balls.

Fault diagnostic is based on the identification of fault characteristic patterns in the current spectrum: firstly, the presence of a given fault harmonic is detected as a distinct spectral peak; and, secondly, its magnitude is used either to perform a simple threshold test to diagnose the presence/absence of a fault [10], or to quantify its severity [1], [11]. But the dependence of the frequency on the slip (2) can make the application of MCSA difficult in some industrial situations, because the diagnostic indicators change with the motor load [12]. So, a stable regime during the sampling time is required for reliable diagnostics using MCSA. Load oscillations (including those caused by the broken bar itself), imbalances, misalignments, or defective transmissions, can smear the current spectrum [10] and hide the sideband components [13]. Wind generation, motors operating valves [14] or conveyor drives are examples of applications where the continuous changes in the load make diagnosis based on the conventional MCSA techniques difficult. Other cases as belt drives, coal pulverizers, gearboxes, or even specific rotor structures have been reported generating sideband frequencies that behave just like those from breakages in the rotor cage winding [7], [13]-[15]. Diverse solutions have been proposed to overcome these problems: advanced signal processing techniques [16], [17]; the use of other magnitudes such as partial power [18]; reactive current [7]; reactive power [19]; motor efficiency [9]; slot harmonics [8]; repeating the same analysis at two significantly different load levels to discriminate the effect of oscillations induced by the load [13]; or using on-line model-based strategies as in [20].

Transient MCSA (TMCSA) offers a different approach to overcome these difficulties: it relies on the same fault-related harmonic components as MCSA, such as (2), (3), (4) and (5); however, instead of detecting them at a single slip, the whole range of slip values during a speed transient is taken into account to diagnose the fault. Therefore, this approach can be a helpful complement in cases when MCSA fails. However, new tools are needed in TMCSA, because traditional Fourier based techniques are not valid for non-stationary signals. Characteristic patterns generated by different faults in the time-frequency plane have been obtained recently using time-frequency transforms of the stator current, such as the discrete wavelet transform (DWT) [21]-[23]; the continuous wavelet transform (CWT) [24]-[26]; the wavelet packet transform (WPT) [27], [28]; or the Wigner Ville distribution (WVD) [28]-[31].

The use of a full range of slip values gives much more information than analysis at a single slip value. However, this fact complicates the computation and interpretation of fault indicators because it adds a new dimension to spectral analysis: time. Time-frequency representations of the stator current, such as those generated by CWT or WVD, are complex 3D (time, frequency and amplitude) images. They have a high computational cost: the spectrogram used in MCSA has a computational complexity of $\mathrm{O}(N \log N)$ using the fast Fourier transform (FFT) (where $N$ is the number of samples of the current), while time-frequency transforms must perform an FFT at every time slice, thus requiring $\mathrm{O}\left(N^{2} \log N\right)$ operations for the case of maximum overlap between time slices [32]. Moreover, 3D images in the time-frequency domain are more difficult to interpret than a simple frequency-only spectral plot. Neural networks have been used to interpret them in [2], [27], [33]; but extensive training data must be given to the neural network in order to improve its fault recognition capabilities. Wavelet coefficients have been used in [14], [25], and [34]; but, as [14] remarks, the challenge is to be able to distinguish which wavelet coefficients represent a particular faulty condition. The reduction from a 3D to a $2 \mathrm{D}$ image using ridge lines has been proposed in [35], but the simultaneous occurrence of different faults can generate false ridge lines.

All the referenced TMCSA methods also require from the MCSA user a drastic change in how the diagnostic data is interpreted, due to the shift from simple spectrum plots to complex 3D time-frequency images. And in addition to changes in qualitative representation of the fault, the indicators that quantify the fault severity must also be redefined: namely, commercial equipment available for MCSA-based broken bar detection used in the field recommends $-50 \mathrm{~dB} \sim-35 \mathrm{~dB}$ of the sideband harmonics as the threshold level for generating a warning or alarm. In TMCSA there is not even a reference quantity for establishing a threshold. 
To overcome the difficulties that arise in TMCSA (high computing cost and difficult interpretation of the diagnosis data), a new TMCSA method is presented in this paper. It is based on a specific transform of the time-varying current, the polynomial phase transform (PPT), and generates a simple Fourier spectrum, which reduces the computation effort down to MCSA levels, instead of generating a 3D time-frequencyamplitude image. At the same time, this transform allows the user to 'see' the diagnosis information in the same way as in the well known MCSA, which is not possible with the other referenced TMCSA methods. However, in sharp contrast with conventional MCSA, where each spectral line is generated by the fault at a single slip, the spectral lines in the proposed approach concentrate the information collected from a wide range of motor regimes (from stand still to nominal regime). This concentration of information increases the robustness of the diagnostic system, drastically reducing the possibility of false positive diagnostics.

Instead of detecting a single fault frequency, this new method detects the rate of variation of the fault frequency versus slip during a speed transient. In the case of the LSH (2), this rate is simply

$$
\left|\frac{d\left(f_{L S H}(s)\right)}{d s}\right|=2 f_{1}
$$

which, for a supply frequency $f_{l}=50 \mathrm{~Hz}$, has a constant value of $2 \times 50=100 \mathrm{~Hz}$ per slip unit, independently of the motor load and speed. The other types of previously mentioned faults also generate harmonics whose frequency varies linearly with the slip, so giving constant frequency slopes. For example, in the case of a two pole pair IM fed with a supply frequency of $50 \mathrm{~Hz}$, and with bearings of nine balls, the characteristic frequency slopes of faults (2), (3), (4) and (5) are shown in Table I.

\section{TABLE I}

\begin{tabular}{|c|c|c|}
\hline Type of fault & $\begin{array}{l}\text { Characteristic } \\
\text { frequency slope }\end{array}$ & $\begin{array}{c}\text { Value for a IM } \\
\text { with } f_{I}=50 \mathrm{~Hz} \\
p=2, N_{b}=9 \\
\text { (Hz / slip unit) }\end{array}$ \\
\hline $\begin{array}{l}\text { Broken bars } \\
\text { (2) }\end{array}$ & $\left|\frac{d\left(f_{L S H}(s)\right)}{d s}\right|=2 f_{1}$ & 100 \\
\hline $\begin{array}{c}\text { Mixed } \\
\text { eccentricity } \\
\text { (3) }\end{array}$ & $\left|\frac{d f_{M E}(s)}{d s}\right|=\frac{f_{1}}{p}$ & 25 \\
\hline $\begin{array}{l}\text { Outer race } \\
\text { (4) }\end{array}$ & $\left|\frac{d f_{o}(s)}{d s}\right|=0.4 \cdot N_{b} \cdot \frac{f_{1}}{p}$ & 90 \\
\hline $\begin{array}{l}\text { Inner race } \\
(5)\end{array}$ & $\left|\frac{d f_{i}(s)}{d s}\right|=0.6 \cdot N_{b} \cdot \frac{f_{1}}{p}$ & 135 \\
\hline
\end{tabular}

Harmonics components such as (2), (3), (4) and (5) are linearly frequency modulated (LFM) signals, also known as chirps. So, among all the various transformations that can operate on non-stationary signals, it is advisable to choose one that can detect the LFM components of the motor current, and evaluate their parameters (initial frequency and frequency variation rate). The PPT [36] is a mathematical transform that can perform this task using a simple, standard Fourier spectrum: the LFM signal generated by the faulty motor during a speed transient is transformed by the PPT into a signal with a constant frequency, which is processed with a FFT algorithm to obtain the signal's parameters and detect the fault. This method can be applied to any motor fault that generates a frequency which depends linearly on the slip, such as (2), (3), (4) and (5). The PPT has been extensively used in the fields of radar, optics and acoustics for target 
identification. Nevertheless, the authors have not found in the literature any application of this tool for the diagnosis of electrical machines.

A similar approach to generate a constant-frequency signal in transient regime has been recently proposed in [12] by applying a frequency shift to the current, different at each time slice, and proportional to the rotor slip. In contrast, in the method proposed in this paper, this signal is obtained directly by applying the PPT, which relies only on the current values.

The aim of this paper is to introduce the PPT and its application for detecting LFM signals produced by different types of IM faults. The suitability of this diagnostic tool is experimentally tested in the diagnosis of a broken rotor bar.

The structure of this paper is as follows: in Section II, the theoretical basis of the PPT is presented, and its application for detecting LFM signals is discussed. Section III deals with the use and optimization of the PPT for the detection of the LSH produced by a broken bar during the startup transient (LSHst). This is a special case for an LFM signal; previously, the LSHst is characterized in the time-frequency domain. Section IV applies the proposed method to the experimental analysis of two different commercial threephase motors, both with broken bars, and one healthy motor. Section V presents the conclusions.

\section{THE DISCRETE POLYNOMIAL-PHASE TRANSFORM}

\section{A. The continuous polynomial-phase transform of a polynomial phase signal}

Let's consider a signal having constant amplitude and continuous phase, such as

$$
x(t)=A \exp (j \phi(t)) \quad 0 \leq t \leq T .
$$

According to the Weierstrass approximation theorem, any continuous function $\phi(t)$ on a closed interval $[0, T]$ can be uniformly approximated by polynomials, so

$$
x(t)=A \exp (j \phi(t))=A \cdot \exp \left(j 2 \pi \sum_{m=1}^{M} a_{m} t^{m}\right) \quad 0 \leq t \leq T
$$

what is known as a signal with polynomial phase (PP). The $M$-order polynomial-phase transform $\left(\mathrm{PPT}_{M}\right)$ is designed to estimate the coefficients of the polynomial phase in (8). It is defined [36] as the Fourier transform (FT) over the interval $[0, T]$ of the function

$$
\mathrm{P}_{M}[x(t), \tau]=\prod_{q=0}^{M-1}\left[x^{\$ q}(t-q \tau)\right]^{\left(\begin{array}{c}
M-1 \\
q
\end{array}\right)}
$$

where

$$
x^{\$ q}(t)= \begin{cases}x(t), & \text { if } q \text { is even } \\ x^{*}(t), & \text { if } q \text { is odd }\end{cases}
$$

$\tau$ is the delay time, and (.)* denotes complex conjugation. So, the $\mathrm{PPT}_{M}$ of the real function $x(t)$ is a function of two variables, frequency $f$ and delay $\tau$, given by

$$
\operatorname{PPT}_{M}[x(t), f, \tau]=\int_{0}^{T} \mathrm{P}_{M}[x(t), \tau] \exp (-j 2 \pi f t) d t
$$




\section{B. The continuous PPT of an LFM signal}

LFM signals, such as (2), (3), (4) and (5), are a particular case of polynomial phase signals, with $\phi(t)$ being a polynomial of degree $M=2(8)$. Their phase and instantaneous frequency (which is the derivative of the phase), are given by

$$
\begin{aligned}
x(t) & =A \exp \left(j 2 \pi\left(b t^{2} / 2+a t\right)\right) & \text { LFM signal } \\
\phi(t) & =2 \pi\left(b t^{2} / 2+a t\right) & \text { Phase } \\
\phi^{\prime}(t) & =2 \pi(b t+a) & \text { Instantaneous frequency }
\end{aligned}
$$

where $b$ is the LFM rate in Hz/s, and $a$ is the initial LFM frequency.

The PPT of order 2 of the signal $x(t), \mathrm{PPT}_{2}[x(t), f, \tau]$, known as the ambiguity transform, is the FT over the interval $[0, T]$ of the function (9) with order $M=2$. This function has a particularly simple expression

$$
\mathrm{P}_{2}[x(t), \tau]=x(t) \cdot x^{*}(t-\tau)
$$

and its FT is given by

$$
\mathrm{PPT}_{2}[x(t), f, \tau]=\int_{0}^{T} x(t) x^{*}(t-\tau) \exp (-j 2 \pi f t) d t .
$$

The effect of the transform (15) is to reduce in one order the degree of the phase polynomial of the LFM signal $x(t)$. This generates a new signal with a constant frequency

$$
\begin{aligned}
& \mathrm{P}_{2}[x(t), \tau]= \\
& =A \cdot \exp \left(j 2 \pi\left(\frac{b t^{2}}{2}+a t\right)\right) \cdot A^{*} \cdot \exp \left(-j 2 \pi\left(\frac{b(t-\tau)^{2}}{2}+a(t-\tau)\right)=\right. \\
& =\left\{|A|^{2} \exp \left(j 2 \pi\left(\frac{b \tau^{2}}{2}+a \tau\right)\right)\right\} \cdot \exp (j 2 \pi(b \tau) t)= \\
& =B \cdot \exp (j 2 \pi(b \tau) t) .
\end{aligned}
$$

The frequency of this new signal is simply the product of the LFM rate $b$ and the delay $\tau$

$$
\begin{gathered}
x(t)=A \exp \left(j 2 \pi\left(b t^{2} / 2\right)+a t\right) \\
\Downarrow \\
\mathrm{P}_{2}[x(t), \tau]=B \exp (j 2 \pi(b \tau) t) .
\end{gathered}
$$

The LFM rate, $b$, can then be estimated with the following procedure: firstly, fix $\tau>0$; and, secondly, compute the FT of $\mathrm{P}_{2}[x(t), \tau]$. The spectrum will show a peak exactly at a frequency $f=b \cdot \tau$, which gives an estimation of $b$ as $f / \tau$. That is

$$
\hat{b}=\frac{1}{\tau} \underset{f}{\arg \max }\left\{\left\|\mathrm{PPT}_{2}[x(t), f, \tau]\right\|\right\} \mathrm{Hz} / \mathrm{s} .
$$




\section{The discrete PPT (DPT) of a LFM signal}

If the LFM signal $x(t)$ is sampled with a sampling interval $\Delta t$, giving a vector $\mathbf{x}$ of $N$ samples, then its discrete polynomial-phase transform of order $2, \operatorname{DPT}_{2}[\mathbf{x}, f, \tau]$ [37] is defined, in close analogy with (11), as:

$$
\mathrm{DPT}_{2}[\mathbf{x}, f, \tau]=\sum_{n=\tau+1}^{N} x[n] x^{*}[n-\tau] \exp (-j 2 \pi n f \Delta t)
$$

For a given value of delay samples $\tau$ (positive integer), (20) is just the Discrete Fourier Transform (DFT) of the sequence $\mathrm{DP}_{2}[\mathbf{x}, \tau]$, defined as

$$
\mathrm{DP}_{2}[\mathbf{x}, \tau]=x[n] x^{*}[n-\tau] \quad \tau<n \leq N
$$

The estimation of the LFM rate $b$ is then

$$
\hat{b}=\frac{1}{\tau \Delta t} \underset{f}{\arg \max }\left\{\left\|\mathrm{DPT}_{2}[\mathbf{x}, f, \tau]\right\|\right\} \mathrm{Hz} / \mathrm{s}
$$

which is valid for any positive integer $\tau$. In [36] it has been shown that the optimal value of $\tau$ is

$$
\tau_{\text {opt }}=0.5 \mathrm{~N}
$$

where $\tau_{\text {opt }}$ is the value that best approximates the Cramer-Rao lower bound for the variance of the estimated phase coefficients in the presence of additive noise [36]. In [38] this choice is confirmed when based on a resolution capability analysis. This procedure has been applied to estimate the parameters of LFM signals in [39]. Signals with random amplitude, such as

$$
x(t)=A(t) \exp (j \phi(t)) \quad 0 \leq t \leq T
$$

have been analyzed in [40]. [38] estimates the parameters of multicomponent polynomial-phase signals, such as

$$
x(t)=\sum_{k=1}^{K}\left(A_{k} \exp \left(j 2 \pi \sum_{m=1}^{M} a_{k, m} t^{m}\right)\right) .
$$

To assess the suitability of the described procedure to characterize the LSHst, the procedure will be first applied first to a pure, synthetic LFM signal; and then, in the next section, to the LSHst produced by a broken bar. In the case of a real signal, such as the LSHst extracted from the motor current, the signal is first converted into a complex form similar to (7) (analytic signal), using the Hilbert transform, as in [17], [41]. This eliminates the negative frequencies (symmetrical to the positive frequencies) in real signals, and avoids interference terms in the DPT spectrum.

D. Characterization of a pure LFM signal using the DPT

A synthetic LFM cosine signal, with an initial frequency of $50 \mathrm{~Hz}$ and sweep rate of $-50 \mathrm{~Hz} / \mathrm{s}$,

$$
x(t)=\cos \left(2 \pi 50\left(t-t^{2} / 2\right)\right)
$$


has been sampled during one second at $1 \mathrm{kHz}$, giving $N=1000$ samples and $\Delta t=10^{-3}$ seconds. It has been represented in

Fig. 1, together with its FT.
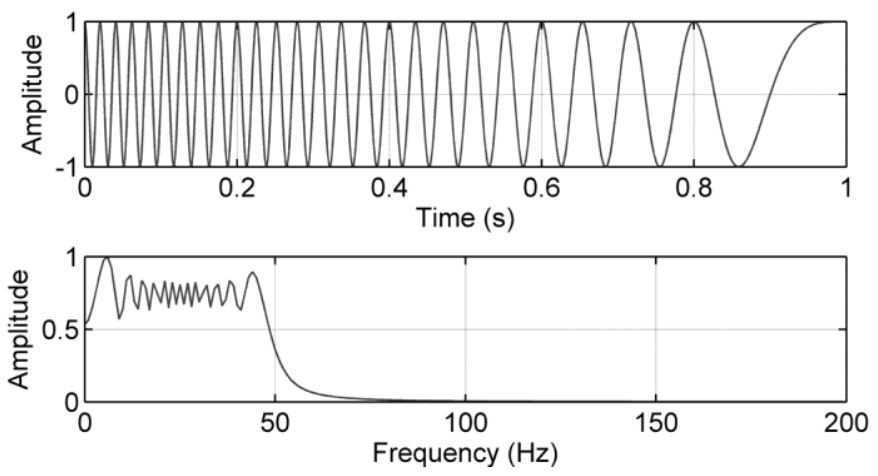

Fig. 1. LFM cosine (top) and its spectrum (bottom).

The spectrum of the $\mathrm{DPT}_{2}$ of the LFM cosine signal (26), using a delay of $\tau=500$ samples, is shown in Fig. 2. It presents a sharp peak at a frequency value of $-25 \mathrm{~Hz}$. The estimation of the LFM rate (19) gives

$$
\hat{b}=\frac{1}{\tau \Delta t} \underset{f}{\arg \max }\left\{\left\|\mathrm{DPT}_{2}[x(t), f, \tau]\right\|\right\}=\frac{-25}{500 \cdot 10^{-3}}=-50 \mathrm{~Hz} / \mathrm{s}
$$

which is exactly the LFM rate of the signal (26).

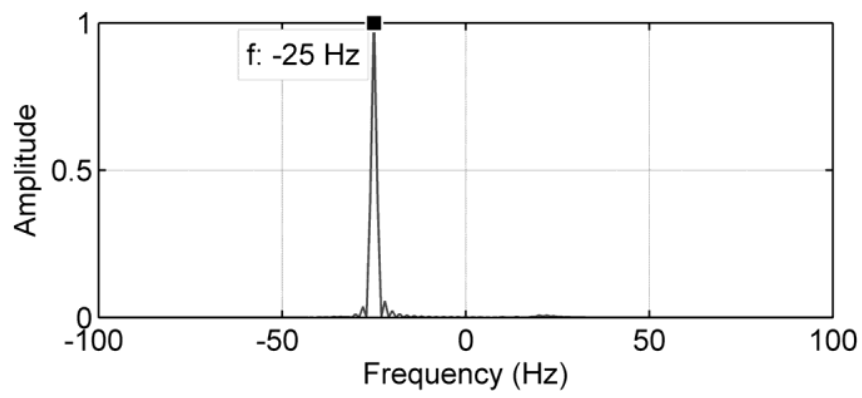

Fig. 2. Spectrum of the $\mathrm{DPT}_{2}$ of the LFM cosine signal.

\section{THE DISCRETE PPT OF THE LSHST}

In this section, the DPT is applied to establish the characteristic pattern of a broken bar fault using a synthetic LSHst. Before the application of the DPT to the LSHst it is worthwhile analyzing the time frequency evolution of this component.

A. Time-frequency characterization of the LSHst

Fig. 3 shows the evolution of the frequency of the LSHst (2) during the startup transient, from slip $s=1$ to $s \approx 0$. 


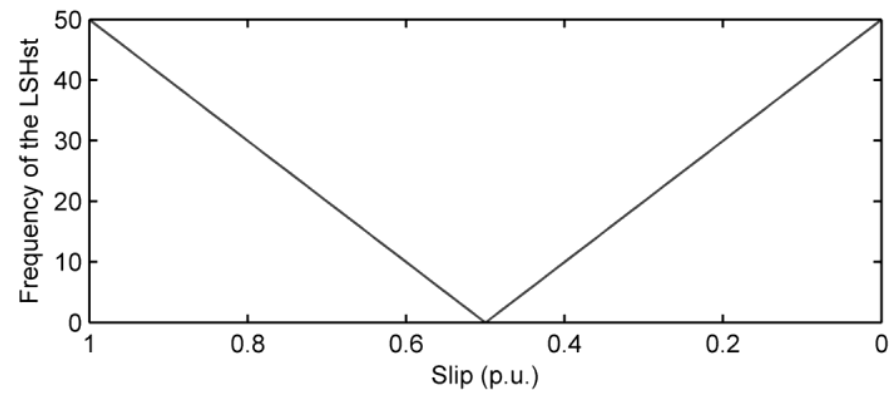

Fig. 3. Evolution of the frequency of the LSHst as a function of the rotor slip.

The evolution of the LSHst has been analyzed by Riera-Guasp et al. [42]. Fig. 4 shows this evolution during the startup transient of a simulated two pole pair machine rated $1.1 \mathrm{~kW}, 400 \mathrm{~V}$, with a broken rotor bar, considering only the fundamental space harmonic of its windings, and sampled during two seconds at 5 $\mathrm{kHz}$. Both the speed and the slip of the motor during the transient are also shown in Fig. 4. A detailed description of the numerical model and of the simulated machine can be found in [42]. In this reference some characteristics of the LSHst relevant for the method proposed in this paper are justified: the LSHst consists of two consecutive chirps, the first with decreasing frequency and the second with increasing frequency. The end of the first chirp coincides with the origin of the second, at $s=0.5$; at this time the frequency of the LSHst is null.
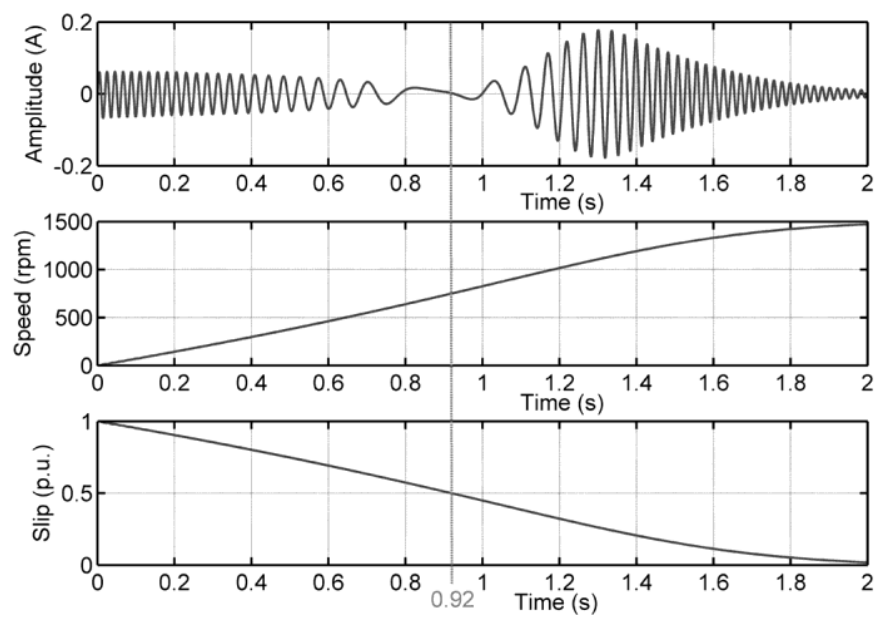

Fig. 4. Amplitude of the LSHst (top), motor speed (middle), and motor slip (bottom) during the startup transient of a simulated motor. The vertical line corresponds to the time when the slip $s=0.5$ is reached.

\section{B. $D P T_{2}$ of the LSHst}

The LSHst, shown in Fig. 4, is not a pure, constant amplitude LFM signal, but a V-shaped FM signal, so it would be necessary to approximate the signal using (25) and not (12). As [36] states, this type of signal is very difficult to estimate, since the second derivative of the phase is discontinuous at the vertex, and the higher order derivatives do not exist at this point. For this type of signals, [36] proposes the use of a 7-th order phase polynomial, and the reduction of $\tau_{\text {opt }}(23)$ to a small value, in order to localize the effect of the discontinuity. Moreover, the LSHst is a V-shaped FM signal with respect to the slip, not to time; although during most of the startup transient the slip is approximately proportional to time.

One of the goals of the present work, carried out in this subsection, is to evaluate the feasibility of estimating the LSHst parameters as two consecutive LFM signals with a second order DPT instead of a much more complex 7-th order transform. 
The LSHst, shown in Fig. 2, has been sampled during two seconds at $5 \mathrm{kHz}$, which gives $N=10000$ samples, and $\Delta t=2 \cdot 10^{-4}$ seconds. As [36] indicates, a value of $\tau$ smaller than (23) must be used with this signal, in order to localize the effect of the discontinuity at the vertex of the $\mathrm{V}$-shape. After extensive numerical simulations, a value of $\tau=0.1 \cdot N=1000$ delay samples has been selected, instead of $\tau=0.5 \cdot N=5000$ delay samples given by (23), which coincides with [36].

The DPT2 of the LSHst (Fig. 5) clearly shows the presence of two LFM signals with opposite frequency rates, the positive rate signal being the most energetic. This pattern fits perfectly with the theoretical evolution of the LSHst during startup, as stated in Section III.

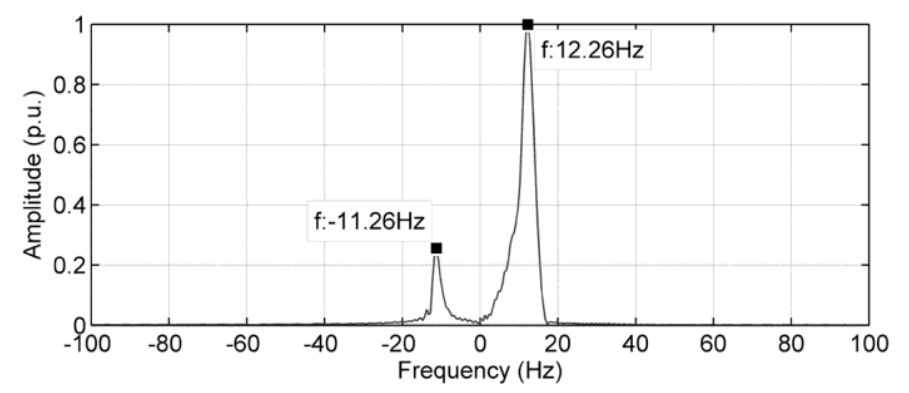

Fig. 5. Spectrum of the $\mathrm{DPT}_{2}$ of the LSHst.

Once the presence of this characteristic pattern has been detected, the variation rate of the frequency versus the slip can be computed to assess if the detected LFM signals verify (6). This method can be used to confirm the diagnosis of broken bar failure. The first LFM component of the LSHst has been selected to this end, because it is easily located in the time axis: from $t=0$ to the time at which a slip $s=0.5$ is reached (vertical line in Fig. 4). The LFM rate of this component (19) is

$$
\hat{b}_{1}=\frac{1}{1000 \cdot\left(2 \cdot 10^{-4}\right)}(-11.26)=-56.3 \mathrm{~Hz} / \mathrm{s} .
$$

The LFM rate is measured in $\mathrm{Hz} /$ second. To assess the presence of a broken bar fault using (6), this value must be converted from $\mathrm{Hz} /$ second to $\mathrm{Hz} /$ slip unit. To perform this conversion, it is necessary to know the seconds/slip unit ratio. The average value of this ratio can be approximately obtained using the time at which a slip value $s=0.5$ is reached. In this case, this time is 0.92 seconds, so

$$
\left|\frac{\Delta f_{L S H s t 1}}{\Delta s_{1}}\right|=\left|\hat{b}_{1} \frac{0.92}{0.5}\right|=56.3 \frac{0.92}{0.5}=103.59 \mathrm{~Hz} / \text { slip unit . }
$$

The theoretical rate of variation of the frequency versus the slip is (6) $2 f_{1}=100 \mathrm{~Hz} / \mathrm{slip}$ unit. The first LFM signal approximates very well this value, so the diagnostic of bar breakage is confirmed.

These results suggest that the combined use of, first, the detection of the characteristic pattern of two LFM signals with rate of variation of opposite sign, and, second, the measurement of the frequency-slip rate of the first LFM component of the LSHst (in case of a positive detection), allow for the correct diagnosis of bar breakages using the proposed method. The results also show that this process can be accomplished with a simple DPT of degree two applied to the LSHst in the time domain, using the slip information to confirm the fault in case of a positive detection. In the following section, this method will be validated experimentally by testing commercial induction motors. 


\section{EXPERIMENTAL VALIDATION}

The proposed method has been applied to the analysis of two commercial induction motors, one with two pole pairs and the other with one pole pairs. Their data are given in the appendixes A and B, respectively. The test equipment, displayed in Fig. 6, consists of a current transformer, a Yokogawa DL750 oscilloscope and a personal computer connected to it via an intranet network. Experimental tests have been carried out under two different conditions: healthy state and faulty condition (in which a single bar has been broken by drilling a hole).

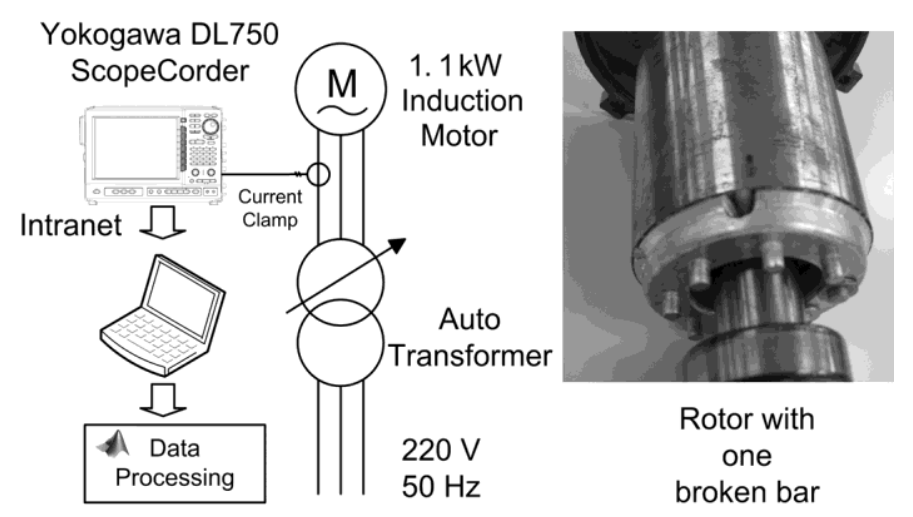

Fig. 6. Experimental setup (left) and motor with a broken bar (right) used for the validation of the proposed methodology.

A limit of the method is the need of a minimum length for the startup to avoid both the influence of the initial electromagnetic transient, taking place after the connection of every machine, and the border effects, which in the earlier stage of the startup transient can mask completely the sideband components. As a guideline, with starting times above 0.5 seconds, the method is suitable.

\section{A. General schema of the analysis via DPT 2 of a motor with broken bars}

The proposed method to detect bar breakages in a squirrel cage motor using the $\mathrm{DPT}_{2}$ can be summarized as:

1)Extraction of the LSHst from the startup current of the motor, using the DWT of the current [42], [43].

2)Computation of the $\mathrm{DPT}_{2}$ of the LSHst, by means of the squared modulus of the FFT of the transformed signal (21). This transform reduces the order of the phase polynomial by one order, converting a chirp into a constant frequency signal. This stage is very fast and easy to compute, because it involves just a single product of the original signal and a copy delayed by a fixed number of samples, followed by the FFT of this product.

3)Identification of the broken bar pattern in the spectrum of the $\mathrm{DPT}_{2}$ : two peaks with opposite frequency rates. This method is akin to the well known identification procedure of the same fault in MCSA, the detection of two sideband components around the fundamental component.

4)In case of positive identification, the presence of the fault can be further assessed by comparing the slope of the detected chirp components with the theoretical value (6). Again, this process parallels the one employed in MCSA, where the frequency of the sideband harmonics is compared with the theoretical harmonic, (which depends on the motor slip, unlike in the proposed method).

\section{B. Analysis via $D P T_{2}$ of the two pole pair IM with one broken bar}

Fig. 7 shows the current of the first commercial motor (Appendix A) with a broken bar, tested during a startup transient. The motor is unloaded and has been fed with a reduced voltage of $160 \mathrm{~V}$ to achieve a longer startup transient. The startup current was recorded during two seconds using a sampling frequency of $10 \mathrm{kHz}$, giving $N=20000$ samples and $\Delta t=10^{-4}$ seconds. 

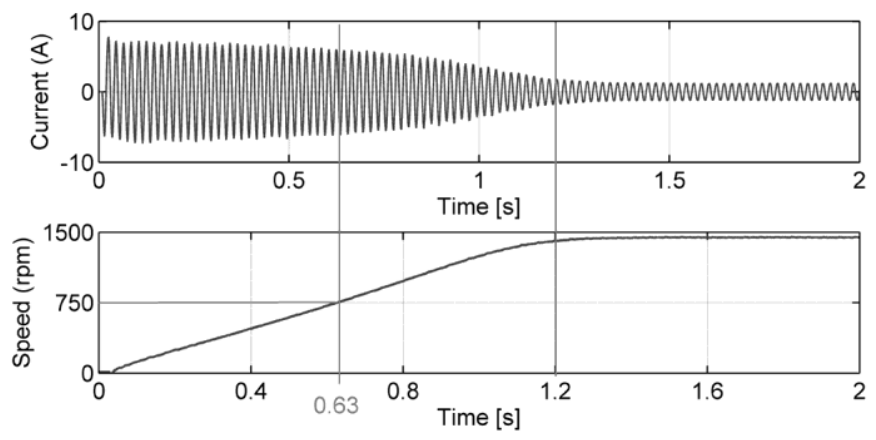

Fig. 7. Current (top) and speed (bottom) of the experimental two pole pair motor with a broken bar during the startup transient. The vertical lines mark the time when the slip $s=0.5$ and the end of the startup transient.

\section{1) Extraction of the LSHst from the startup current}

The LSHst must be first extracted before performing an analysis with the $\mathrm{DPT}_{2}$. There are several methods proposed in the literature, including [29], [41]-[45], for extracting components from transient signals. In this work, we use the method proposed in [41] and [42], which is specifically designed for extracting the LSHst from the startup transient current. In this work the LSHst is extracted using the DWT, with the dmeyer wavelet as the mother wavelet and $n_{f}=7$ decomposition levels. As demonstrated in [42], the decomposition level of the approximation signal that includes the left sideband harmonic is given by

$$
n_{f}=\text { Integer }\left[\log \left(f_{S} / f_{1}\right) / \log (2)\right]=7
$$

where $f_{s}$ denotes the sampling frequency of the current signal $\left(f_{s}=10 \mathrm{kHz}\right)$. Fig. 8 shows the approximation signal with level 7 of the wavelet decomposition of the startup current, which contains the LSHst; as demonstrated in [42], in the case of rotor asymmetry, this approximation signal fits the LSHst; so it will be used as the experimental LSHst of the faulty machine to validate the proposed approach.

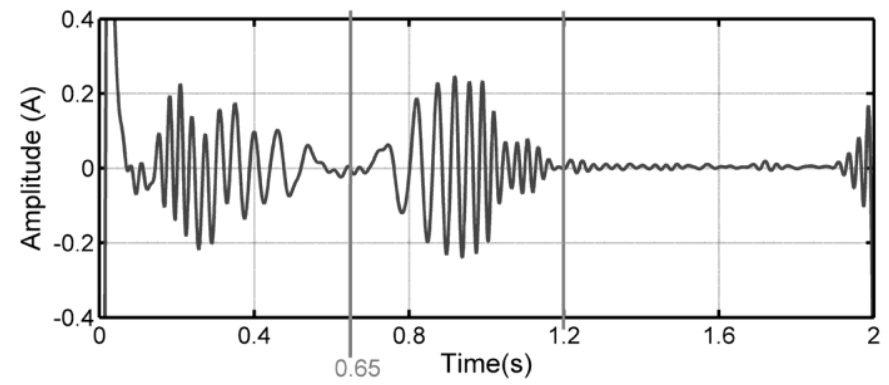

Fig. 8. LSHst of the two pole pair motor with a broken bar extracted using the approximation signal of the DWT of the motor current. The first vertical line marks the estimated time when the motor reaches a slip $s=0.5$.

2) Computation of the DPT 2 of the LSHst

The $\mathrm{DPT}_{2}$ of this experimental LSHst has been computed using $\tau=0.1 \cdot N=2000$ delay samples.

3) Identification of the broken bar pattern in the spectrum of the $D P T_{2}$

The spectrum of the $\mathrm{DPT}_{2}$ of the experimental LSHst of the faulty machine (Fig. 9) shows a characteristic pattern, very easy to identify, which can be described qualitatively as follows: the pattern consists of two clear predominant peaks, one corresponding to a negative frequency and the other corresponding to a positive frequency, with the positive peak being higher than the negative peak. 


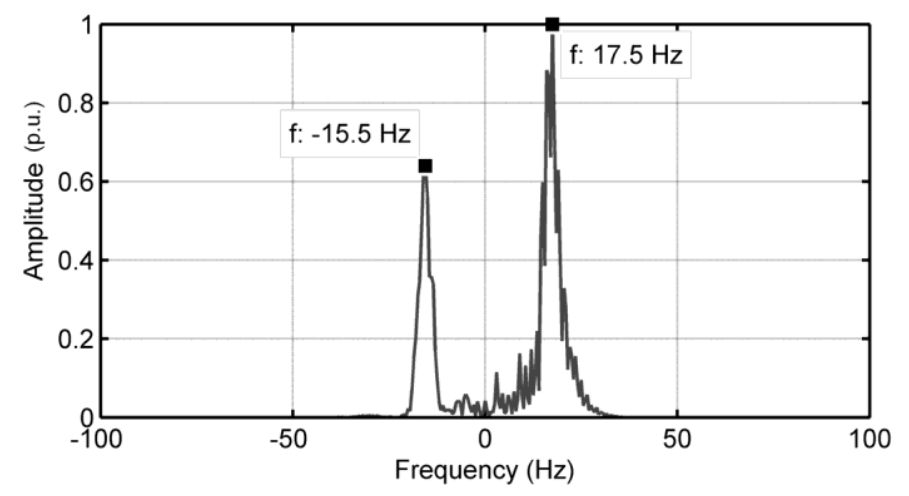

Fig. 9. Spectrum of the $\mathrm{DPT}_{2}$ of the experimental LSHst in the two pole pair motor with a broken bar.

These two peaks have a clear physical meaning; they are produced by the presence in the analyzed LSHst of two predominant LFM signals with opposite sweep frequency rates, the signal with the positive rate being the most energetic. This pattern clearly indicates the presence of a broken bar fault as was justified in Section III.

4) Confirmation of the detected fault by comparing the estimated chirp rate of harmonics with the theoretical rate

Once detected the presence of this characteristic pattern, the rate of variation of the frequency versus the slip can be computed to assess if the detected LFM signals verify (6). This can be used to confirm the failure diagnostic. The rate of the LFM component of the LSHst with negative slope can be calculated by means of Fig. 9 and (19)

$$
\hat{b}_{1}=\frac{1}{2000 \cdot 10^{-4}}(-15.5)=-77.5 \mathrm{~Hz} / \mathrm{s} \text {. }
$$

This component presents a change in slip from 1 to 0.5 in 0.63 seconds (see Fig. 7), so the ratio

$$
\left|\frac{\Delta f_{L S H s t 1}}{\Delta s_{1}}\right|=\left|\hat{b}_{1} \frac{0.63}{0.5}\right|=77.5 \frac{0.63}{0.5}=97.65 \mathrm{~Hz} / \text { slip unit }
$$

gives the variation rate of the experimental LSHst frequency vs. slip in Hz per slip unit. This value is very close to the theoretical value (6), which confirms that this pattern corresponds to a broken bar fault.

These considerations are also applied to the analysis of the positive peak of the spectrum of the experimental LSHst. From Fig. 9 we obtain

so, from Fig. 7

$$
\hat{b}_{2}=\frac{1}{2000 \cdot 10^{-4}}(17.5)=87.5 \mathrm{~Hz} / \mathrm{s}
$$

$$
\left|\frac{\Delta f_{L S H s t 2}}{\Delta s_{2}}\right| \approx\left|\hat{b}_{2} \frac{1.2-0.63}{0.5}\right|=87.5 \frac{0.57}{0.5}=99.75 \mathrm{~Hz} / \text { slip unit }
$$

which is a value that is also very close to the theoretical value (6). 
In some industrial facilities the speed of the motor during the startup transient may be unavailable. A single current probe is sufficient to measure the motor current, and this can easily be inserted in the power line. However, to measure the motor speed it is necessary to connect an encoder to the motor shaft and this is more difficult to implement. So, in some facilities, the motor speed is not measured. Reliable speed estimators can be used to calculate the motor speed, such as the one based on slot harmonics proposed in [16], [44], [46] or the adaptive scheme, based on the measured currents and voltages, used in [20]. Nevertheless, it is still possible to confirm the diagnosis of broken bars fault without measuring or estimating the instantaneous motor speed: it suffices to obtain, from the graphical representation of the LSHst, the duration of both chirp components (which vanish at slips $s=0.5$ and $s=1$, respectively, as stated in Section III). In Fig. 8 these times have been estimated as $t=0.65$ seconds for the component with a negative slope, and $t=1.2-0.65$ seconds for the component with a positive slope, being slightly different from the measured values. This gives a variation rate of the LSHst frequency vs. slip unit of

$$
\left|\frac{\Delta f_{L S H s t 1}}{\Delta s_{1}}\right|=\left|\hat{b}_{1} \frac{0.65}{0.5}\right|=75 \frac{0.65}{0.5}=97.5 \mathrm{~Hz} / \mathrm{slip} \text { unit }
$$

for the negative slope component and

$$
\left|\frac{\Delta f_{L S H s t 2}}{\Delta s_{2}}\right|=\left|\hat{b}_{2} \frac{1.2-0.65}{0.5}\right|=87.5 \frac{0.55}{0.5}=96.25 \mathrm{~Hz} / \mathrm{slip} \text { unit }
$$

for the positive slope component These values are again very close to the theoretical values (6), which confirms that the detected pattern corresponds to a broken bar fault.

\section{Analysis via $\mathrm{DPT}_{2}$ of the one pole pairs IM with one broken bar}

The second commercial motor that has been tested is a one pole pair IM, with a broken bar. In this case, instead of testing it unloaded and with a reduced supply voltage, it has been fed with nominal voltage supply and mechanically connected to a high inertia load (a dynamo machine electrically disconnected), to achieve a longer startup transient, as shown in Fig. 10. The startup current and the speed (Fig. 11) have been recorded during 10 seconds using a sampling frequency of $10 \mathrm{kHz}$, giving $N=100000$ samples and $\Delta t=10^{-4}$ seconds.

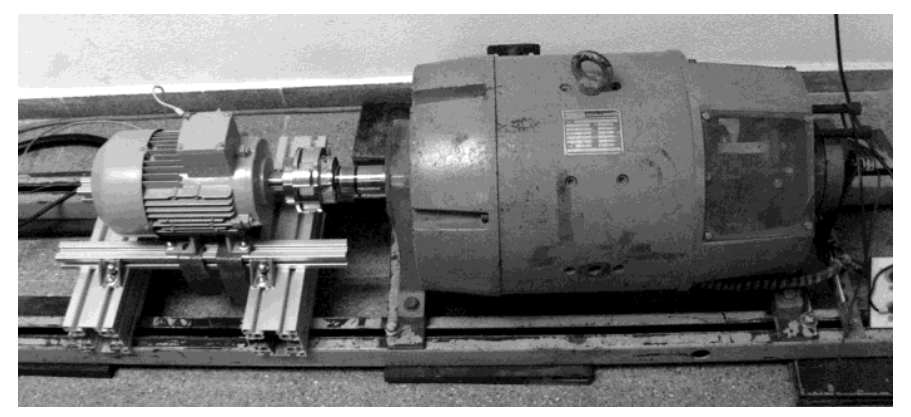

Fig. 10. Experimental test rig for the one pole pair motor (left), coupled mechanically to a high inertia dynamo machine (right).

To diagnose the motor, the four steps of the method are applied to this motor. 

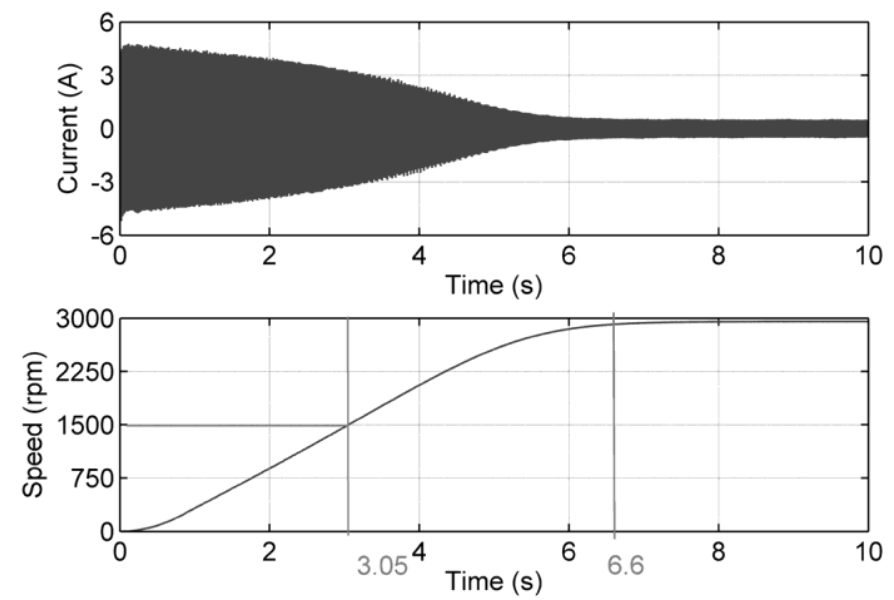

Fig. 11. Current (top) and speed (bottom) of the experimental two pole pair motor with a broken bar during the startup transient. The vertical lines mark the time when the slip $s=0.5$ and the end of the startup transient.

1) Extraction of the LSHst from the startup current of the motor

The method for extracting the LSHst harmonic has been applied exactly as explained in Section IV.B.1. The approximation signal with level seven of the previous wavelet decomposition is shown in Fig. 12.

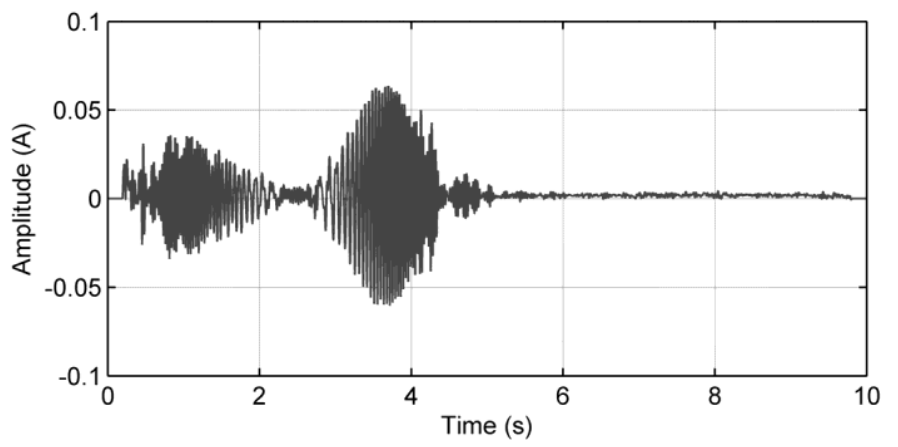

Fig. 12. LSHst of the one pole pair motor with a broken bar extracted using the approximation signal of the DWT of the motor current.

2) Computation of the DPT $T_{2}$ of the LSHst

The $\mathrm{DPT}_{2}$ of this experimental LSHst has been computed using $\tau=0.1 \cdot N$ delay samples, as explained in Section IV.B.2. In this case $\tau=0.1 \cdot 10^{5}=10^{4}$ samples.

3) Identification of the broken bar pattern in the spectrum of the DPT

The spectrum of the $\mathrm{DPT}_{2}$ of the experimental LSHst is shown in Fig. 13.

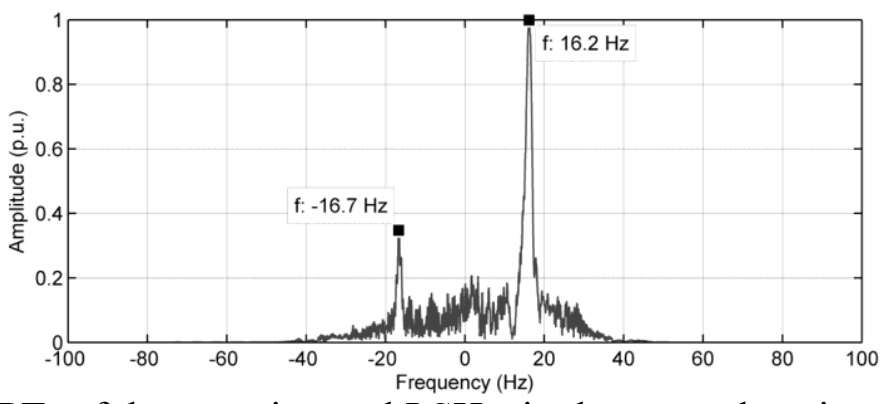

Fig. 13. Spectrum of the $\mathrm{DPT}_{2}$ of the experimental LSHst in the one pole pair motor with a broken bar. 
These two peaks are produced by the presence in the analyzed LSHst of two predominant LFM signals with opposite sweep frequency rates, where the positive rate signal is the most energetic. This pattern clearly indicates the presence of a broken bar fault as was justified in Section III.

4) Confirmation of the detected fault by comparing the estimated chirp rate of harmonics with the theoretical rate

Once detected the characteristic pattern of a broken bar fault in the spectrum of the $\mathrm{DPT}_{2}$, the rate of variation of the frequency versus the slip can be computed to assess that the detected LFM signals verify (6). The rate of the LFM component of the LSHst with negative slope can be calculated from Fig. 13 and (19) as

$$
\hat{b}_{1}=\frac{1}{10000 \cdot 10^{-4}}(-16.7)=-16.7 \mathrm{~Hz} / \mathrm{s}
$$

This component presents a change in slip from 1 to 0.5 in 3.05 seconds (see Fig. 11), so the ratio

$$
\left|\frac{\Delta f_{L S H s t 1}}{\Delta s_{1}}\right|=\left|\hat{b}_{1} \frac{3.05}{0.5}\right|=16.7 \frac{3.05}{0.5}=101.87 \mathrm{~Hz} / \mathrm{slip} \text { unit }
$$

gives the rate of variation of the experimental LSHst frequency vs. slip in Hz per slip unit. This value is very close to the theoretical value (6), which confirms that this pattern corresponds to a broken bar fault.

These considerations are also applied to the analysis of the positive peak of the spectrum of the experimental LSHst. From Fig. 13 we obtain

so, from Fig. 11

$$
\hat{b}_{2}=\frac{1}{10000 \cdot 10^{-4}}(16.2)=16.2 \mathrm{~Hz} / \mathrm{s}
$$

$$
\left|\frac{\Delta f_{L S H s t 2}}{\Delta s_{2}}\right| \approx\left|\hat{b}_{2} \frac{6.4-3.05}{0.5}\right|=16.2 \frac{3.35}{0.5}=108.86 \mathrm{~Hz} / \text { slip unit }
$$

a value which is also very close to the theoretical value (6).

D. Analysis via DPT 2 of a healthy motor

A healthy motor, with the same characteristics and operating conditions as the faulty motor tested in section IV.B (two pole pair, Appendix A), has also been analyzed using the procedure outlined in Section IV.A. Fig. 14 shows the current and the speed during the startup transient, sampled using the same parameters as in the case of the faulty motor. To diagnose the motor, the four steps of the method are applied. 

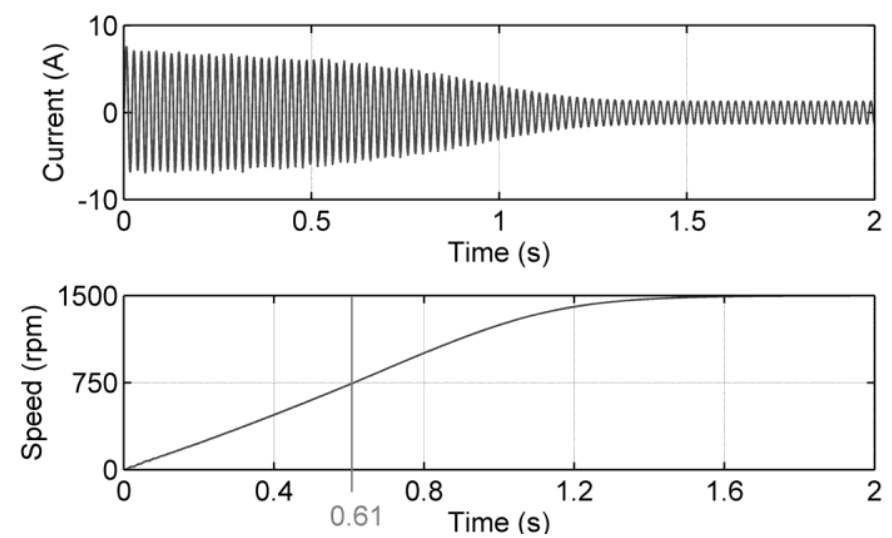

Fig. 14. Current (top) and speed (bottom) of the experimental healthy motor during the startup transient. The vertical line corresponds to the time when slip $s=0.5$ is reached.

1) Extraction of the LSHst from the startup current

The method for extracting the LSHst harmonic has been applied exactly as explained in Section IV.B.1. The approximation signal with level seven of the previous wavelet decomposition, which should contain the expected LSHst, is shown in Fig. 15.

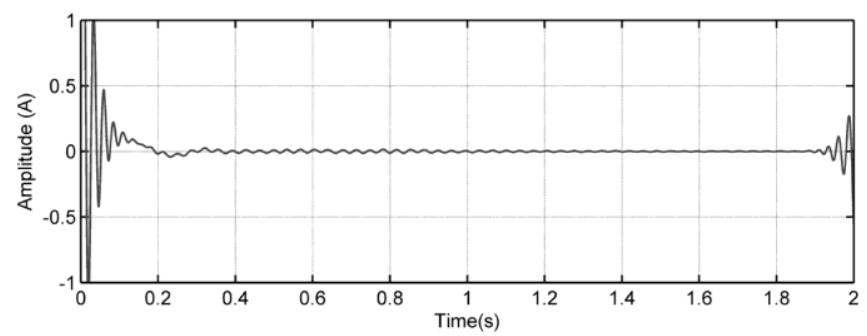

Fig. 15. LSHst of the healthy motor using the approximation signal of the DWT of the motor's current.

2) Computation of the DPT 2 of the LSHst

The $\mathrm{DPT}_{2}$ of this experimental LSHst has been computed using $\tau=0.1 \cdot N$ delay samples, as explained in Section IV.B.2.

3) Identification of the broken bar pattern in the spectrum of the $\mathrm{DPT}_{2}$

The spectrum of the DPT2 of the LSHst is shown in Fig. 16, where a single peak appears. This pattern does not correspond to the characteristic pattern of a broken bar fault (two LFM signals with opposite sweep rates), so in this case the diagnostic is the absence of a broken bar fault, as verified by visual inspection of the machine's rotor. In this case, it is therefore not necessary to proceed to step 4 (confirmation of the fault).

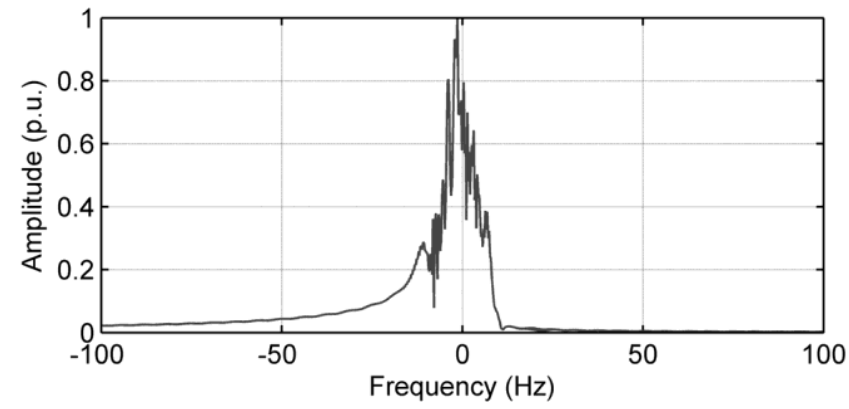

Fig. 16. Spectrum of the $\mathrm{DPT}_{2}$ of the experimental LSHst in the experimental healthy motor.

E. Representation of the DPT 2 spectrum amplitudes in $d b$

To facilitate the recognition of the fault patterns the amplitudes of the sideband harmonics of Fig. 9 and 
Fig. 16 can be represented as $\mathrm{dB}$ values with respect to the signal's energy (Fig. 17), in a similar way to MCSA, where the broken bars fault appear as sideband harmonics with respect to the grid frequency mains component.
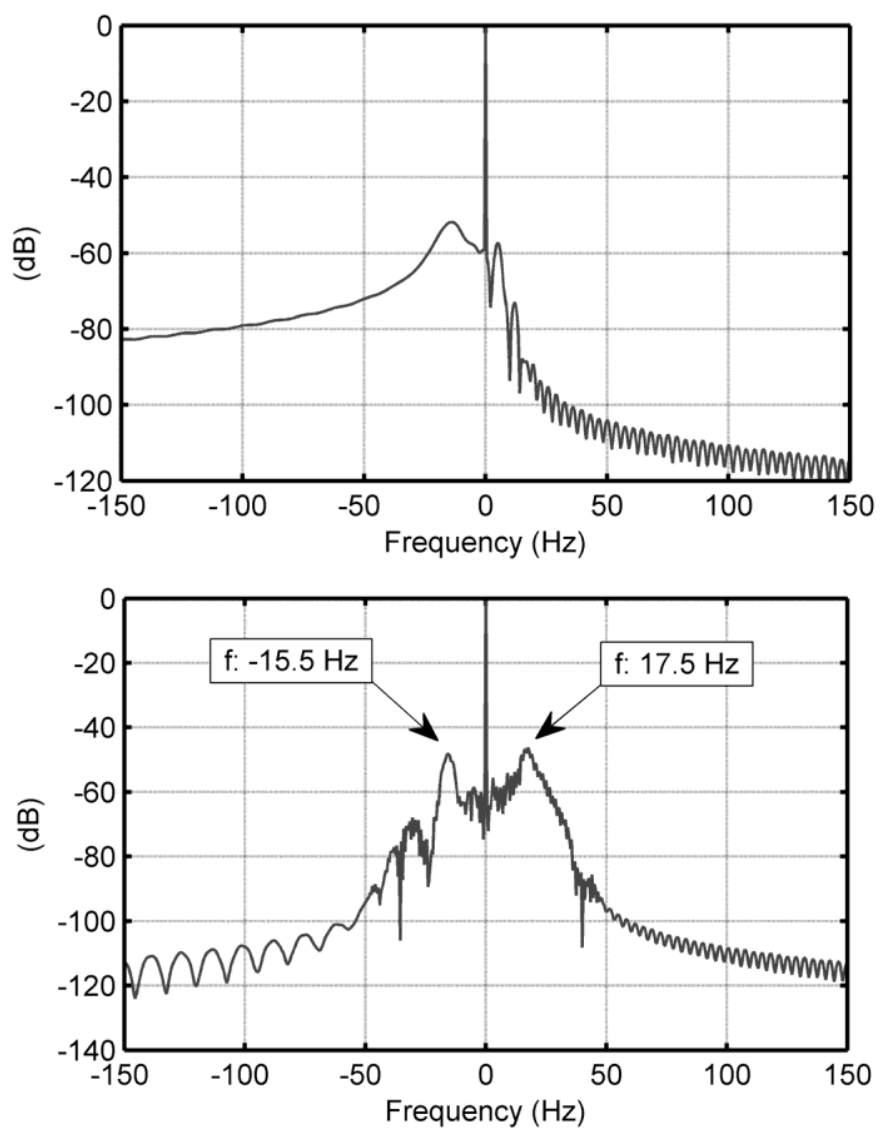

Fig. 17. Spectrum of the DPT2 of the healthy (top) and fault (bottom) two pole pair motor, with the amplitudes represented as $\mathrm{dB}$ with respect to the signal energy.

\section{CONCLusions}

In this paper, a new methodology for the diagnosis of induction motors based on the discrete polynomial transform has been presented. Firstly, it has been shown that different types of faults such as mixed eccentricities, bar breakages or bearing damage produce components in the stator current whose frequency varies linearly with the slip. When the machine undergoes a transient regime with variable speed, the fault components behave as linear frequency modulated signals. Each type of fault has a characteristic constant frequency-slip slope which is independent of the load conditions and motor characteristics. The new diagnostic method proposed in this paper relies on the ability of the DPT to detect and discriminate LFM components in the current signal, under time-varying conditions. The feasibility of the proposed approach has been experimentally tested in the particular case of broken bars detection during a startup transient.

It has been also shown that the computational complexity of the DPT is very low, compared with other TMCSA methods, because it does not need to generate any 3D time-frequency-amplitude image; just a single FFT of the transformed current signal is sufficient to obtain the characteristic pattern and frequencyslip slope of the fault components. This feature enables a reliable diagnosis. Another advantage of the proposed method is that the results are presented in a very similar manner to the classical Fourier spectrum: the measured slopes appear as distinct peaks in the DPT spectrum, where each type of fault generates characteristic spectral lines. So this method can complement the classical MCSA method for detecting motor faults in cases when the diagnostic is not clear (due to load oscillations, etc.). 
A limitation of the method is the need for a minimum startup time, to avoid both the influence of the initial electromagnetic transient and the border effects of the transform. As a guideline, startup times need to be greater than 0.5 seconds. This method has a clear application field in the diagnosis of high power machines that start under heavy conditions.

\section{APPENDIX A}

Machine parameters: Three-phase induction motor of $1.1 \mathrm{~kW}, 50 \mathrm{~Hz}, 230 / 400 \mathrm{~V}, 2.7 / 4.6 \mathrm{~A}, 1410 \mathrm{rpm}$, cos $\varphi=0.8$.

\section{APPENDIX B}

Machine parameters: Three-phase induction motor of $1.5 \mathrm{~kW}, 50 \mathrm{~Hz}, 230 / 400 \mathrm{~V}, 3.25 / 5.65 \mathrm{~A}, 2860 \mathrm{rpm}$, $\cos \varphi=0.85$.

\section{REFERENCES}

[1] A. Bellini, F. Filippetti, G. Franceschini, C. Tassoni, and G. B. Kliman, "Quantitative evaluation of induction motor broken bars by means of electrical signature analysis," IEEE Trans. Ind. Appl., vol. 37, pp. 1248-1255, 2001.

[2] A. Bellini, F. Filippetti, C. Tassoni, and G. A. Capolino, "Advances in Diagnostic Techniques for Induction Machines," IEEE Trans. Ind. Electron., vol. 55, pp. 4109-4126, 2008.

[3] S. Grubic, J. M. Aller, B. Lu, and T. G. Habetler, "A Survey on Testing and Monitoring Methods for Stator Insulation Systems of Low-Voltage Induction Machines Focusing on Turn Insulation Problems," IEEE Trans. Ind. Electron., vol. 55, pp. 4127-4136, 2008.

[4] C. Bruzzese, "Analysis and Application of Particular Current Signatures (Symptoms) for Cage Monitoring in Nonsinusoidally Fed Motors With High Rejection to Drive Load, Inertia, and Frequency Variations," IEEE Trans. Ind. Electron., vol. 55, pp. 4137-4155, 2008.

[5] M. Blodt, P. Granjon, B. Raison, and G. Rostaing, "Models for Bearing Damage Detection in Induction Motors Using Stator Current Monitoring," IEEE Trans. Ind. Electron., vol. 55, pp. 1813-1822, 2008.

[6] R. N. Andriamalala, H. Razik, L. Baghli, and F. M. Sargos, "Eccentricity Fault Diagnosis of a DualStator Winding Induction Machine Drive Considering the Slotting Effects," IEEE Trans. Ind. Electron., vol. 55, pp. 4238-4251, 2008.

[7] G. R. Bossio, C. H. De Angelo, J. M. Bossio, C. M. Pezzani, and G. O. García, "Separating Broken Rotor Bars and Load Oscillations on IM Fault Diagnosis Through the Instantaneous Active and Reactive Currents," IEEE Trans. Ind. Electron., vol. 56, pp. 4571-4580, 2009.

[8] A. Khezzar, M. Y. Kaikaa, M. E. K. Oumaamar, M. Boucherma, and H. Razik, "On the Use of Slot Harmonics as a Potential Indicator of Rotor Bar Breakage in the Induction Machine," IEEE Trans. Ind. Electron., vol. 56, pp. 4592-4605, 2009.

[9] L. Frosini and E. Bassi, "Stator Current and Motor Efficiency as Indicators for Different Types of Bearing Faults in Induction Motors," IEEE Trans. Ind. Electron., vol. 57, pp. 244-251, 2010.

[10]W. T. Thomson and M. Fenger, "Current signature analysis to detect induction motor faults," IEEE Industry Applications Magazine, vol. 7, pp. 26-34, 2001.

[11]G. Y. Sizov, A. Sayed-Ahmed, C. C. Yeh, and N. A. O. Demerdash, "Analysis and Diagnostics of Adjacent and Nonadjacent Broken-Rotor-Bar Faults in Squirrel-Cage Induction Machines," IEEE Trans. Ind. Electron., vol. 56, pp. 4627-4641, 2009.

[12]A. Stefani, A. Bellini, and F. Filippetti, "Diagnosis of Induction Machines' Rotor Faults in TimeVarying Conditions," IEEE Trans. Ind. Electron., vol. 56, pp. 4548-4556, 2009.

[13]M. C. Ian and R. Wendell, "Using Current Signature Analysis Technology to Reliably Detect Cage Winding Defects in Squirrel-Cage Induction Motors," IEEE Trans. Ind. Appl., vol. 43, pp. 422-428, 2007. 
[14]H. Douglas, P. Pillay, and A. K. Ziarani, "Broken rotor bar detection in induction machines with transient operating speeds," IEEE Trans. Energy Convers., vol. 20, pp. 135-141, 2005.

[15]A. Bellini, F. Filippetti, G. Franceschini, C. Tassoni, R. Passaglia, M. Saottini, G. Tontini, M. Giovannini, and A. Rossi, "On-field experience with online diagnosis of large induction motors cage failures using MCSA," IEEE Trans. Ind. Appl., vol. 38, pp. 1045-1053, 2002.

[16]B. Trajin, J. Regnier, and J. Faucher, "Comparison Between Stator Current and Estimated Mechanical Speed for the Detection of Bearing Wear in Asynchronous Drives," IEEE Trans. Ind. Electron., vol. 56, pp. 4700-4709, 2009.

[17]R. Puche-Panadero, M. Pineda-Sanchez, M. Riera-Guasp, J. Roger-Folch, E. Hurtado-Perez, and J. Perez-Cruz, "Improved Resolution of the MCSA Method Via Hilbert Transform, Enabling the Diagnosis of Rotor Asymmetries at Very Low Slip," IEEE Trans. Energy Convers., vol. 24, pp. 52-59, 2009.

[18]J. Faiz and M. Ojaghi, "Instantaneous-Power Harmonics as Indexes for Mixed Eccentricity Fault in Mains-Fed and Open/Closed-Loop Drive-Connected Squirrel-Cage Induction Motors," IEEE Trans. Ind. Electron., vol. 56, pp. 4718-4726, 2009.

[19]M. Drif and A. J. M. Cardoso, "The Use of the Instantaneous-Reactive-Power Signature Analysis for Rotor-Cage-Fault Diagnostics in Three-Phase Induction Motors," IEEE Trans. Ind. Electron., vol. 56, pp. 4606-4614, 2009.

[20]C. H. De Angelo, G. R. Bossio, S. J. Giaccone, M. I. Valla, J. A. Solsona, and G. O. Garcia, "Online Model-Based Stator-Fault Detection and Identification in Induction Motors," IEEE Trans. Ind. Electron., vol. 56, pp. 4671-4680, 2009.

[21]M. Riera-Guasp, J. A. Antonino-Daviu, M. Pineda-Sanchez, R. Puche-Panadero, and J. Perez-Cruz, "A General Approach for the Transient Detection of Slip-Dependent Fault Components Based on the Discrete Wavelet Transform," IEEE Trans. Ind. Electron., vol. 55, pp. 4167-4180, 2008.

[22]J. Cusido, L. Romeral, J. A. Ortega, J. A. Rosero, and A. Garcia Espinosa, "Fault Detection in Induction Machines Using Power Spectral Density in Wavelet Decomposition," IEEE Trans. Ind. Electron., vol. 55, pp. 633-643, 2008.

[23]A. Ordaz-Moreno, R. de Jesus Romero-Troncoso, J. A. Vite-Frias, J. R. Rivera-Gillen, and A. GarciaPerez, "Automatic Online Diagnosis Algorithm for Broken-Bar Detection on Induction Motors Based on Discrete Wavelet Transform for FPGA Implementation," IEEE Trans. Ind. Electron., vol. 55, pp. 2193-2202, 2008.

[24]F. Briz, M. W. Degner, P. Garcia, and D. Bragado, "Broken Rotor Bar Detection in Line-Fed Induction Machines Using Complex Wavelet Analysis of Startup Transients," IEEE Trans. Ind. Appl., vol. 44, pp. 760-768, 2008.

[25]R. Supangat, N. Ertugrul, W. L. Soong, D. A. Gray, C. Hansen, and J. Grieger, "Detection of broken rotor bars in induction motor using starting-current analysis and effects of loading," IEE Proceedings Electric Power Applications, vol. 153, pp. 848-855, 2006.

[26]I. P. Tsoumas, G. Georgoulas, E. D. Mitronikas, and A. N. Safacas, "Asynchronous Machine Rotor Fault Diagnosis Technique Using Complex Wavelets," IEEE Trans. Energy Convers., vol. 23, pp. 444459, 2008.

[27]M. Khan and M. A. Rahman, "Development and Implementation of a Novel Fault Diagnostic and Protection Technique for IPM Motor Drives," IEEE Trans. Ind. Electron., vol. 56, pp. 85-92, 2009.

[28]E. G. Strangas, S. Aviyente, and S. S. H. Zaidi, "Time-Frequency Analysis for Efficient Fault Diagnosis and Failure Prognosis for Interior Permanent-Magnet AC Motors," IEEE Trans. Ind. Electron., vol. 55, pp. 4191-4199, 2008.

[29]J. A. Rosero, L. Romeral, J. A. Ortega, and E. Rosero, "Short-Circuit Detection by Means of Empirical Mode Decomposition and Wigner-Ville Distribution for PMSM Running Under Dynamic Condition," IEEE Trans. Ind. Electron., vol. 56, pp. 4534-4547, 2009. 
[30]M. Blodt, D. Bonacci, J. Regnier, M. Chabert, and J. Faucher, "On-Line Monitoring of Mechanical Faults in Variable-Speed Induction Motor Drives Using the Wigner Distribution," IEEE Trans. Ind. Electron., vol. 55, pp. 522-533, 2008.

[31]A. Lebaroud and G. Clerc, "Classification of Induction Machine Faults by Optimal Time-Frequency Representations," IEEE Trans. Ind. Electron., vol. 55, pp. 4290-4298, 2008.

[32]R. Büssow, "An algorithm for the continuous Morlet wavelet transform," Mechanical Systems and Signal Processing, vol. 21, pp. 2970-2979, 2007.

[33]A. Sadeghian, Z. Ye, and B. Wu, "Online Detection of Broken Rotor Bars in Induction Motors by Wavelet Packet Decomposition and Artificial Neural Networks," IEEE Trans. Instrum. Meas., vol. 58, pp. 2253-2263, 2009.

[34]O. A. Mohammed, N. Y. Abed, and S. Ganu, "Modeling and Characterization of Induction Motor Internal Faults Using Finite-Element and Discrete Wavelet Transforms," IEEE Transactions on Magnetics, vol. 42, pp. 3434-3436, 2006.

[35]S. Rajagopalan, J. M. Aller, J. A. Restrepo, T. G. Habetler, and R. G. Harley, "Analytic-WaveletRidge-Based Detection of Dynamic Eccentricity in Brushless Direct Current (BLDC) Motors Functioning Under Dynamic Operating Conditions," IEEE Trans. Ind. Electron., vol. 54, pp. 14101419, 2007.

[36]S. Peleg and B. Porat, "Estimation and classification of polynomial-phase signals," IEEE Transactions on Information Theory, vol. 37, pp. 422-430, 1991.

[37]S. Peleg and B. Friedlander, "The discrete polynomial-phase transform," IEEE Transactions on Signal Processing, vol. 43, pp. 1901-1914, 1995.

[38]S. Barbarossa, A. Scaglione, and G. B. Giannakis, "Product high-order ambiguity function for multicomponent polynomial-phase signal modeling," IEEE Transactions on Signal Processing, vol. 46, pp. 691-708, 1998.

[39]S. Peleg and B. Porat, "Linear FM signal parameter estimation from discrete-time observations," IEEE Transactions on Aerospace and Electronic Systems, vol. 27, pp. 607-616, 1991.

[40]O. Besson, N. Ghogho, and A. Swami, "Parameter estimation for random amplitude chirp signals," IEEE Transactions on Signal Processing, vol. 47, pp. 3208-3219, 1999.

[41]M. Pineda-Sanchez, M. Riera-Guasp, J. A. Antonino-Daviu, J. Roger-Folch, J. Perez-Cruz, and R. Puche-Panadero, "Instantaneous Frequency of the Left Sideband Harmonic During the Start-Up Transient: A New Method for Diagnosis of Broken Bars," IEEE Trans. Ind. Electron., vol. 56, pp. 4557-4570, 2009.

[42]M. Riera-Guasp, J. A. Antonino-Daviu, J. Roger-Folch, and M. P. Molina Palomares, "The Use of the Wavelet Approximation Signal as a Tool for the Diagnosis of Rotor Bar Failures," IEEE Trans. Ind. Appl., vol. 44, pp. 716-726, 2008.

[43]M. Pineda-Sanchez, M. Riera-Guasp, J. A. Antonino-Daviu, J. Roger-Folch, J. Perez-Cruz, and R. Puche-Panadero, "Diagnosis of Induction Motor Faults in the Fractional Fourier Domain," IEEE Trans. Instrum. Meas., Accepted for future publication, Digital Object Identifier 10.1109/TIM.2009.2031835.

[44]W. Zhou, T. G. Habetler, and R. G. Harley, "Bearing Fault Detection via Stator Current Noise Cancellation and Statistical Control," IEEE Transactions on Industrial Electronics, vol. 55, pp. 42604269, 2008.

[45]T. Kijewski-Correa and A. Kareem, "Performance of Wavelet Transform and Empirical Mode Decomposition in Extracting Signals Embedded in Noise," Journal of Engineering Mechanics, vol. 133, pp. 849-852, 2007.

[46]M. Yasser Abdel-Rady Ibrahim, "A Hybrid-Type Variable-Structure Instantaneous Torque Control With a Robust Adaptive Torque Observer for a High-Performance Direct-Drive PMSM," IEEE Trans. Ind. Electron., vol. 54, pp. 2491-2499, 2007.

M. Pineda-Sanchez (M'02) was born in 1962 in Albacete (Spain). He received his Dipl. Ing. and Dr. Ing. degrees in electrical engineering from the Universidad Politécnica de 
Valencia (Spain) in 1985 and 2004, respectively. He joined the faculty of the Universidad Politécnica de Valencia in 1987 as Associate Professor in the Department of Electrical Engineering, in the area of theory and control of electrical machines. His research interests include electrical machines and drives, induction motor diagnostics, numerical simulation of electromagnetic fields, and software development.

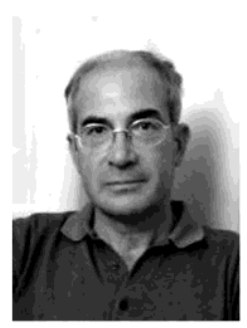

M. Riera-Guasp (M'95) received an M.Sc. degree in industrial engineering and the Ph.D. degree in electrical engineering from the Universidad Politécnica de Valencia (Spain) in 1981 and 1987, respectively. Currently he is Associate Pprofessor in the Department of Electrical Engineering of the Universidad Politécnica de Valencia. His research interests include condition monitoring of electrical machines, applications of the wavelet theory to electrical engineering, and efficiency in electric power applications.

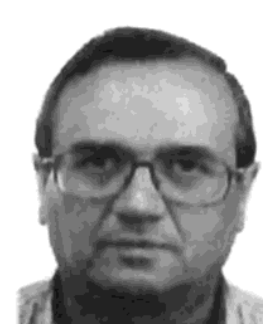

J. Roger-Folch (M'03) obtained his M.Sc. degree in electrical engineering in 1970 from the Universidad Politécnica de Cataluña and his Ph.D in 1980 from the Universidad Politécnica de Valencia, Spain. From 1971 to 1978 he worked in the electrical industry as project engineer. He joined the Universidad Politécnica de Valencia in 1978 and is currently Professor of electrical installations and machines. His main research areas are numerical methods (F.E.M. and others) applied to the design and maintenance of electrical machines and equipment

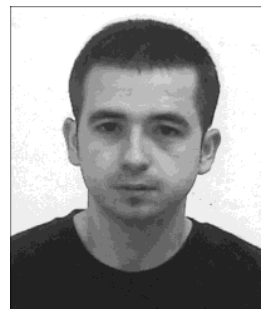

Jose A. Antonino-Daviu (M'04) received the M.Sc. degree in Electrical Engineering from the Universidad Politecnica de Valencia in 2000 and the Ph.D. degree in Electrical Engineering in 2006. He worked in the private sector, being involved in several international projects. Currently, he is Associate Professor in the School of Industrial Engineering of the mentioned University, where he develops his docent and research work. His primary research interests are condition monitoring of electric machines, wavelet theory and its application to fault diagnosis and design and optimization of electrical installations and systems.

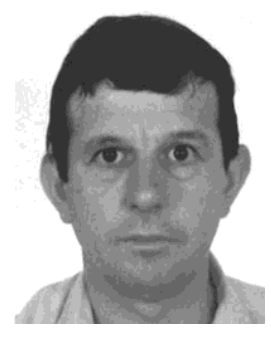

J. Perez-Cruz (M'09) obtained his M.Sc. in electrical engineering in 1997 from the Universidad Politécnica de Valencia and his Ph.D. in 2006 from the same university. From 1970 to 1992 he worked in the electrical industry as an electrical technician in the field of industrial systems maintenance and automation. In 1992 he joined the Universidad Politécnica de Valencia and is currently Associate Professor of electrical installations and machines. His research interests focus on induction motor diagnostics and maintenance, numerical modelling, and automation of industrial installations.

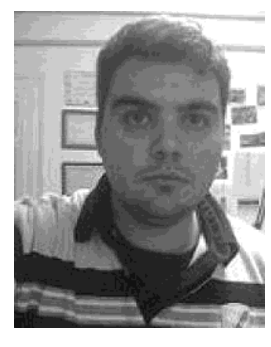

R. Puche-Panadero (M'09) obtained his M.Sc. in automatic and electronic engineering in 2003 from the Universidad Politécnica de Valencia. From 2003 to 2006 he worked in an Innovate European Automation Project as a developer of the SCADA programs and control panels. He joined the Universidad Politécnica de Valencia in 2006 and is currently Assistant Professor of machine control. His research interests focus on induction motor diagnostics and maintenance, numerical modelling, and automation of industrial installations 